\title{
NEGATIVE ION-BASED NEUTRAL INJECTION ON DIII-D
}

\author{
by \\ L.D. STEWART, D.K. BHADRA, \\ A.P. COLLERAINE and JINCHOON KIM
}

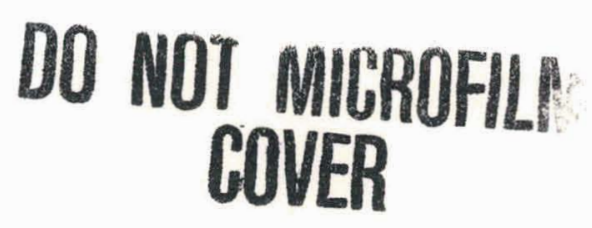

JANUARY 1990

\section{GENERAL ATOMICS}




\section{DISCLAIMER}

This report was prepared as an account of work sponsored by an agency of the United States Government. Neither the United States Government nor any agency Thereof, nor any of their employees, makes any warranty, express or implied, or assumes any legal liability or responsibility for the accuracy, completeness, or usefulness of any information, apparatus, product, or process disclosed, or represents that its use would not infringe privately owned rights. Reference herein to any specific commercial product, process, or service by trade name, trademark, manufacturer, or otherwise does not necessarily constitute or imply its endorsement, recommendation, or favoring by the United States Government or any agency thereof. The views and opinions of authors expressed herein do not necessarily state or reflect those of the United States Government or any agency thereof. 


\section{DISCLAIMER}

Portions of this document may be illegible in electronic image products. Images are produced from the best available original document. 


\section{DISCLAIMER}

This report was prepared as an account of work sponsored by the United States Government. Neither the United States Government nor any agency thereof, nor any of their employees, makes any warranty, express or implied, or assumes any legal liability or responsibility for the accuracy, completeness, or usefulness of any information, apparatus, product, or process disclosed, or represents that its use would not infringe privately owned rights. Reference herein to any specific commercial product, process, or service by trade name, trademark, manufacturer, or otherwise, does not necessarily constitute or imply its endorsement, recommendation, or favoring by the United States Government or any agency thereof. The views and opinions of authors expressed herein do not necessarily state or reflect those of the United States Government or any agency thereof. 


\title{
NEGATIVE ION-BASED NEUTRAL INJECTION ON DIII-D
}

\author{
by \\ L.D. STEWART, D.K. BHADRA, \\ A.P. COLLERAINE and JINCHOON KIM
}

This is a preprint of a paper to be printed in the Proceedings of the Fifth International Symposium on the Production \& Neutralization of Negative lons \& Beams (October 30th through November 3, 1989), Long Island, N.Y.

\author{
Work supported by \\ Department of Energy \\ Contract DE-AC03-89ER51114
}

GENERAL ATOMICS PROJECTS 4913 \& 3466 JANUARY 1990

\section{GENERAL ATOMICS}


NEGATIVE ION-BASED NEUTRAL INJECTION ON DIII-D*

I. D. Stewart, D. K. Bhadra, A. P. Colleraine, and J. Kim General Atomics, San Diego, Ca. 92138

\section{ABSTRACT}

High energy negative ion-based neutral beam injection is a strong candidate for heating and non-inductive current drive in tokamaks. Many of the questions related to the physics and engineering of this technique remain unanswered. In this paper, we consider the possibility of negative lon-based neutral beam injection on DIII-D. We establish the desired parameter space by examining physics trades. This is combined with potential design constraints and a survey of component technology options to establish an injector concept. Injector performance is estimated assuming particular component technologies, and concept flexibility with respect to incorporating alternate technologies is described.

\section{INTRODUCTION}

Neutral beam injection (NBI) is a principal candidate for plasma heating and for noninductive current drive in tokamaks. However, there are many important NBI physics and engineering issues which still need resolution in order to lay the groundwork for the planning, design and execution of NBI in future applications such as ITER.

The DIII-D tokamak at GA has been suggested as a test-bed on which high energy NBI physics issues might be explored. We have considered the possibility of negative lon-based NBI on DIII-D. To establish the desired parameter space, we have examined the impact of beam energy on potential DIII-D NBI heating and current drive physics experiments. We have looked at potential design constraints and have surveyed component technology options to establish an injector concept. We have estimated injector performance parameters by assuming particular component tcchnologioe. Finally, because the actual infector configuration will depend on future development program direction, we have explored concept flexibility with respect to incorporating alternate technologies.

\section{PHYSICS TRADES}

The existing experimental data base for neutral beam injection into tokamaks extends to beam energles of $\sim 100 \mathrm{keV}$ : an order-ofmagnitude lower than needed for ITER. A study of physics processes, while applying $0.5 \mathrm{MeV}$ injection into DIII-D, would increase confidence in theoretical predictions and in the choices for ITER design parameters.

*Work sponsored in part by the Department of Energy under Contract No. DE-AC03-89ER51114. 
Table I 11sts four physics processes relating to neutral beam injection into a tokamak plasma, and indicates programmatic importance and key DIII-D experiments for each. The two bottom-line physics processes are heating and current drive, and two primary physics processes which directly affect heating and current drive efficiency are multistep ionization and shear-Alfven Instability. The programmatic importance in all cases derives from the choice of neutral beams as the primary current drive engine for ITER.

Table I Physics processes

\begin{tabular}{lll}
\hline \multicolumn{1}{c}{ Process } & \multicolumn{1}{c}{ Importance } & \multicolumn{1}{c}{ Key Experiment } \\
\hline Heating & $\begin{array}{l}\text { Determines ITER mix of } \\
\text { beam and If heating }\end{array}$ & $\begin{array}{l}\text { Inject high } E_{b} \text { beams, ECH and } \\
\text { ICH into same target }\end{array}$ \\
Current drive & $\begin{array}{l}\text { Determines ITER power } \\
\text { needs }\end{array}$ & Amps/watt versus $E_{b}$ \\
$\begin{array}{l}\text { Multistep } \\
\text { Ionization }\end{array}$ & $\begin{array}{l}\text { Determines ITER shine- } \\
\text { through and orbit } \\
\text { losses }\end{array}$ & $\begin{array}{l}\text { Shine-through and penetration } \\
\text { versus } E_{b}\end{array}$ \\
$\begin{array}{l}\text { Shear-Alfven } \\
\text { Instability }\end{array}$ & $\begin{array}{l}\text { Establishes ITER } \\
\text { I-drive efficiency }\end{array}$ & $\begin{array}{l}\text { Search for onset in DIII-D } \\
\text { operating space }\end{array}$ \\
\hline
\end{tabular}

Data on basic heating efficiency and current drive efficiency would allow some confidence in the ITER choices of beam energy, beam power, and supplemental if type and power. A key set of experiments on plasma heating would be the injection of neutral beams, ECH, and ICH into essentially identical plasmas. Recognizing that the method of heating is a primary factor in determining plasma parameters, the approach would be to generate ITER-relevant plasmas in DIII-D using 10 to $20 \mathrm{MW}$ of $80 \mathrm{keV}$ neutral beams, then to apply a megawatt of $\sim 0.5 \mathrm{MeV}$ beams, ECH, or ICH.

Physics processes which influence heating and current drive effectiveness are multistep ionization and possibly the shear-Alfven instablifty. Many predictions of neutral beam effectiveness neglect multistep Ionization and thereby underestimate beam attenuation. With a representation of the true cross section as $\sigma_{g s}(1+\delta)$, where $\sigma_{g s}$ is the ground state cross section, the predicted correction factor $\delta$ is shown in Fig. 1.1 The dotted vertical lines on Fig. 1 and on the following figures show beam energies of $80 \mathrm{keV}$, representing the existing DIII-D infectors, and $400 \mathrm{keV}$, representing a future negative ion-based injector. 


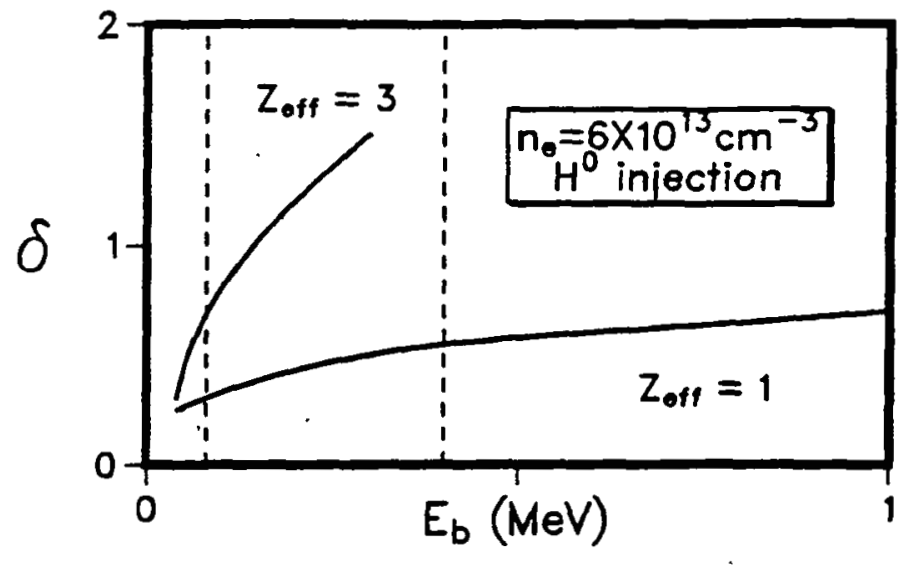

Fig. 1. Excitation-enhancement of the beam stopping cross section.

The predicted $\delta$ is $\sim 1$ for plasma conditions and beam energies of interest on DIII-D, so the real ionization cross section is predicted to be about twice that for the ground state. Because of the strong influence of $\delta$ on penetration and power deposition, particularly for ITER, there is a high premium on experimental verification. The observables on DIII-D will be Balmer alpha emission distribution and shine-through power. Figure 2 shows predicted DIII-D shine-through and orbit losses for quasi-tangential injection and for relevant plasma conditions. 2

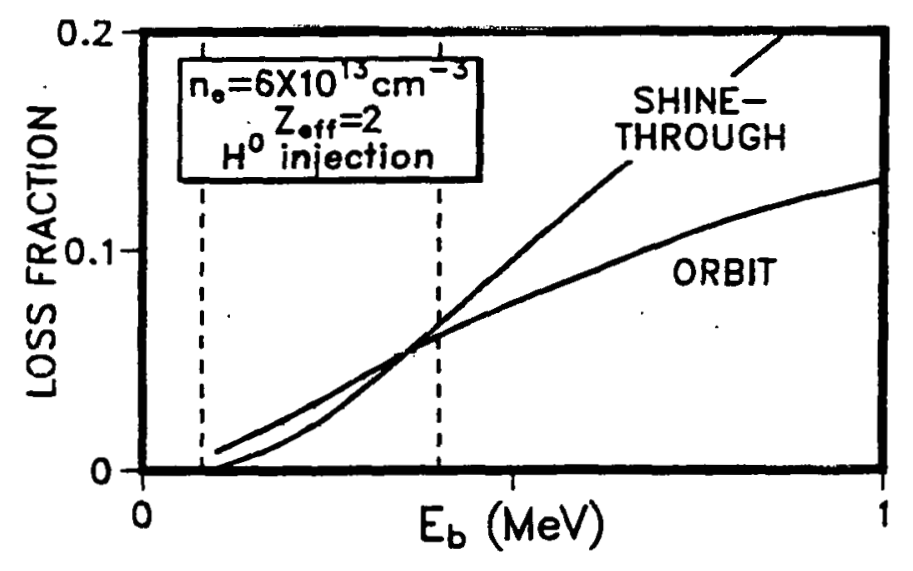

Fig. 2. NBI shine-through and orbit losses.

The theory of the shear-Alfvèn ${ }^{3}$ mode predicts that it should appear in ITER with high energy NBI. 4 What is needed now is data for benchmarking the theory and for establishing the effect of the shear-Alfvèn mode on the confined plasma. Neutral beams are predicted to drive the shear-Alfvèn mode when the ion thermal velocity $\left(v_{1}\right)$, the electron thermal velocity $\left(v_{e}\right)$, the beam ion velocity $\left(v_{b}\right)$ 
and the Alfven speed $\left(v_{a}\right)$ are ordered as $v_{1}<v_{a}<v_{b}<v_{e}$. The conditions on $v_{1}$ and $v_{e}$ are met in tokamak plasmas.

However, in DIII-D with $80 \mathrm{keV} \mathrm{NBI,} \mathrm{the} \mathrm{condition} v_{a}<v_{b}$ is attained only marginally. Because $v_{a}$ scales as $B / \sqrt{n_{e}}$, lowering $v_{a}$ entalls low fleld-high density operation, a disruption-prone and somewhat atypical regime. Injection with $\sim 400 \mathrm{keV}$ beams, on the other hand, allows DIII-D operation in the normal, broader, and more stable operating regime. This is 1llustrated in Fig. 3, a densityfield plot which compares the DIII-D Murakaml scaling with the regimes of $v_{b}>2 v_{a}$ for 80 and $400 \mathrm{keV}$ injection.

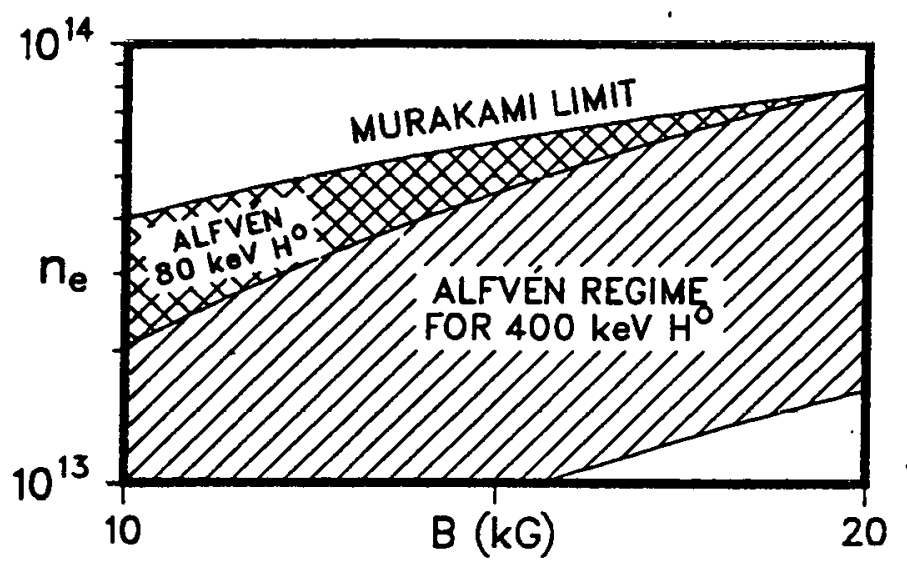

Fig. 3. DIII-D Murakami scaling and regimes of $v_{b}>2 v_{a}$ for 80 andd $400 \mathrm{keV} \mathrm{H} \mathrm{H}^{\circ}$ injection.

Calculated neutral beam current drive efficiency as a function of energy for representative DIII-D plasma conditlons is shown in Fig. 4.2 The curve labeled $\eta_{G}$ is for gross efficlency, the driven current divided by the total neutral power incident on the plasma, and the curve labeled $\eta_{N}$ is for net efficiency, where the neutral power has been corrected for orbit and shine-through losses. Because of their uncertainty, shear-Alfvèn effects have not been incorporated. The efficiencles show a broad maximum at about $400 \mathrm{keV}$ for either $\mathrm{H}^{\circ}$ or $\mathrm{D}^{\circ}$ injection.

Because the initial DIII-D negative fon-based NBI system would be limited in current to that produced by one (or possibly two) sources, a more relevant consideration may be the amount of driven current for a fixed amount of beam current. This is shown in Fig. 5 to level off at about $1 \mathrm{MeV}$, with a knee at $\sim 500$ to $700 \mathrm{keV}$. So although somewhat more beam-driven current could be obtained with $1 \mathrm{MeV}$ injection, there is diminishing return above about $600 \mathrm{keV}$.

\section{INJECTOR DESIGN CONSTRAINTS}

Table II lists principal constraints, their origin and their impact on the design of a negative ion-based neutral beam system for 


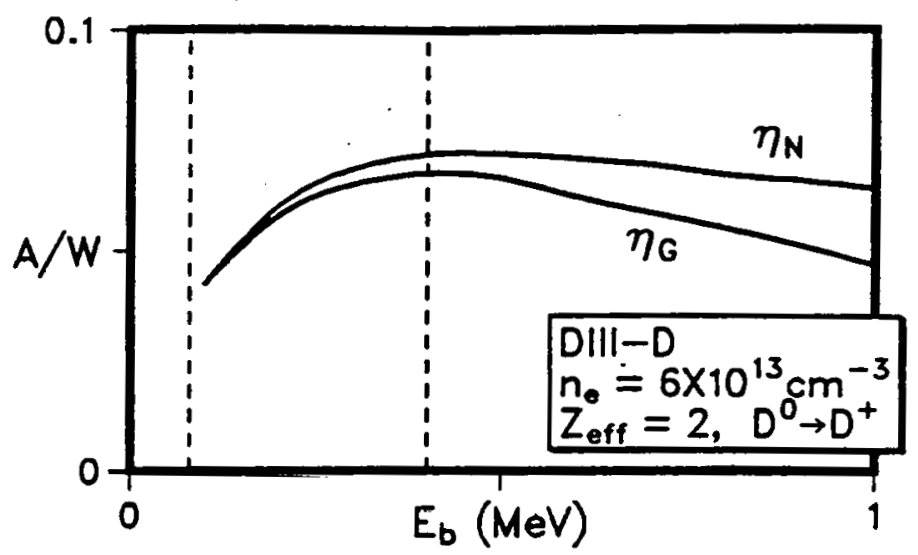

Fig. 4. NBI current drive efficiency.

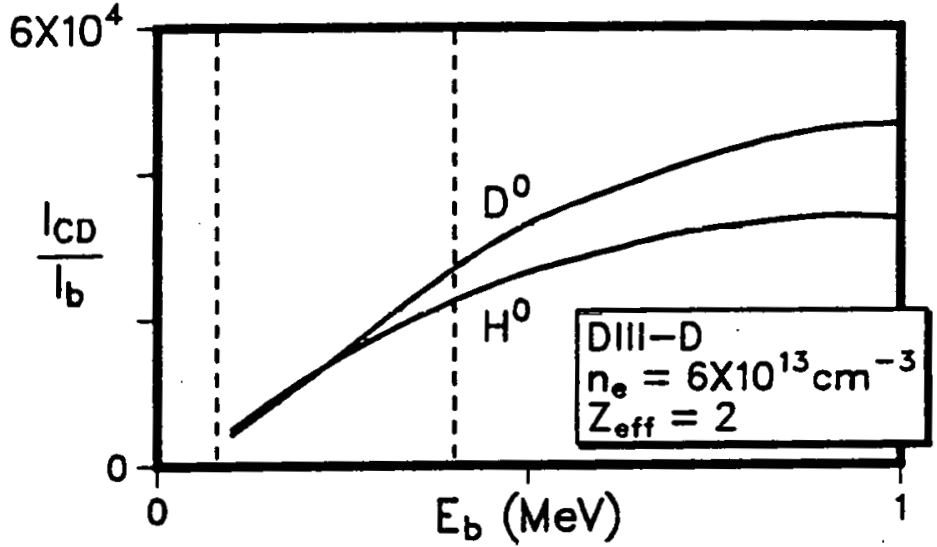

Fig. 5. NBI current drive effectiveness: driven current $\div$ beam current.

Table II Constraints on injector design

\begin{tabular}{|c|c|c|}
\hline Constraint & Orfgin & Impact \\
\hline $\begin{array}{l}\text { Minimize overall } \\
\text { perturbation }\end{array}$ & $\begin{array}{l}\text { DIII-D operations; } \\
\text { total cost }\end{array}$ & $\begin{array}{l}\text { Convert one or two beams } \\
\text { inftially }\end{array}$ \\
\hline $\begin{array}{l}\text { Try to use pres- } \\
\text { ent cryopump }\end{array}$ & Cost & $\begin{array}{l}\text { Basic beamline geometry } \\
\text { fixed; source and stripper } \\
\text { gas loads } \sim \text { present }\end{array}$ \\
\hline Length & Building walls & Little impact on design \\
\hline Shine-through & $\begin{array}{l}\text { Heat dissipation in } \\
\text { DIII-D wall armor }\end{array}$ & $E_{b}$ can be at least $1 \mathrm{MeV}$ \\
\hline Neutrons & $\begin{array}{l}\text { Deuterium beam onto } \\
\text { dumps, calorimeter }\end{array}$ & $\vec{E}_{b}$ can be at least $1 \mathrm{MeV}$ \\
\hline
\end{tabular}


DIII-D. As an overall constraint, the size of this proposed undertaking is bounded by realism on budgets and by the need to avoid interference with DIII-D experimental operations. The scale for Initial modification of beamline, power and cooling systems must not be large. As a consequence, at most one beamline, and more likely one beam, is considered for conversion. For the same reasons, it is desirable to use the existing beamline cryopump. This means the beamline geometry, as well as the gas loading due to the fon source and neutralizer, should be basically similar to the existing positive ion-based injectors.

Three other potential constraints were evaluated. Building walls either are not in the way or can be moved. If care is taken to avoid very low plasma density operation, shine-through can be tolerated up to at least $1 \mathrm{MeV}$. Most neutron generation will occur in the tokamak plasma; most plasma neutron generation will be due to the present energy inputs and not to the additional high energy neutral beam. As a result, neutron radiation is not increased significantly for beam energies at least up to $1 \mathrm{MeV}$.

\section{INJECTOR CONCEPT}

Figure 6 shows side-view layouts of the present positive ion injectors and of our concept for the injector as modified for negative ions. The existing positive ion sources produce an approximately rectangular beam of $12 \times 48 \mathrm{~cm}$ cross section. This geometry matches the entrance ports of DIII-D, and would be maintained in converting to a negative ion system. The existing beamlines have cryopanels in the calorimeter and neutralizer regions. These cryopanels are to be left undisturbed if possible. It does not appear reasonable to adapt the existing 180 degree bending magnet and charged beam dumps. At a minimum, extensive redesign would be required to accommodate the higher beam energy as well as the significant amounts of beam power in both the negative and positive components of the neutralized beam.

In the proposed negative ion system, sizes for the various beamline components have been estimated assuming specific component technologies which accommodate either a $400 \mathrm{keV} \mathrm{H}$ - beam or a $400 \mathrm{keV}$ $D^{-}$beam. We have chosen an extraction energy of $400 \mathrm{keV}$ as a compromise which maximizes physics performance while minimizing technology extrapolation and cost. A $400 \mathrm{keV}$ high voltage system at the current we anticipate $(5 \mathrm{~A})$ is well within present design technology for stackable, modular units.

Starting at the tokamak end of the proposed beamline, the calorimeter region with its cryopanel is unchanged. Upstream from the calorimeter is an fon separator/dump unit. The unit shown has been sized such that either magnetic or electrostatic technology could be accommodated. Upstream from the separator is a stripper with gaps at each end for pumping. The 2 meter length shown for the stripper is that estimated for $\mathrm{H}_{2}$ gas. The 0.8 meters allotted for the accelerator is sufficient for Pierce or $\mathrm{ESQ}^{5}$ technologies. The 


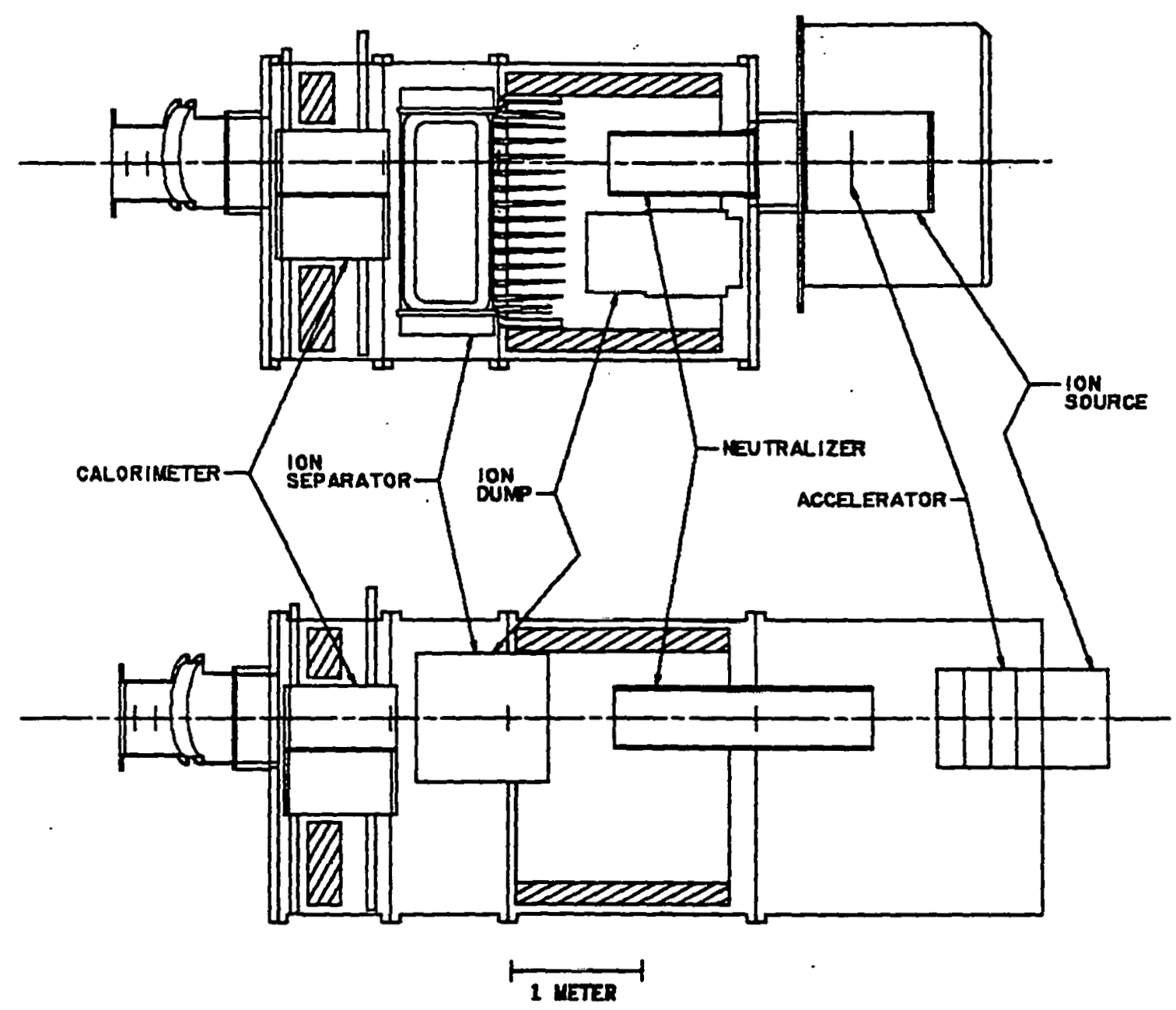

PROPOSED NEGATIVE ION SYSTEM

Fig. 6. Side views of the existing and proposed DIII-D beamlines.

total additional length needed for the negative fon system is provided by adding a 2 meter vacuum chamber segment. The interface of this segment with existing chamber will be as open as possible to maximize conductance between the accelerator and the main cryopanel.

Table III presents performance parameters estimated for the injector concept when assuming $10 \%$ gas efficiency for the fon source, accelerator pumping constrained by a Plerce-like geometry, and an $\mathrm{H}_{2}$ gas stripper. The estimated neutral power includes transmission losses and the power/energy degradation due to stripping in the accelerator. The impact of this stripping is indicated by the full energy and the above-two-thirds energy ( $>270 \mathrm{keV})$ beam fractions in the table. The neutral, positive, and negative fractions 
Table III Estimate performance parameters (one beam)

\begin{tabular}{llll}
\hline \multicolumn{1}{c}{ Parameter } & \multicolumn{1}{c}{ Basis } & HO Value & D Value \\
\hline Extraction energy & $\begin{array}{l}\text { Physics benefits, cost, } \\
\text { technology extrapolation }\end{array}$ & $400 \mathrm{keV}$ & $400 \mathrm{keV}$ \\
Ion current & $\mathrm{H}^{-}$at $20 \mathrm{~mA} / \mathrm{cm}^{2} \times 250 \mathrm{~cm}^{2}$ & $5.0 \mathrm{~A}$ & $3.5 \mathrm{~A}$ \\
Neutral power & Combined loss estimates & $1.1 \mathrm{MW}$ & $0.72 \mathrm{MW}$ \\
Beam fractions: & Cross sections & 0.60 & 0.60 \\
Neutral & Estimate premature stripping & 0.86 & 0.80 \\
Full energy & Estimate premature stripping & 0.92 & 0.89 \\
$>270$ keV & Cross sections & 0.20 & 0.20 \\
Positive & Cross sections & 0.20 & 0.20 \\
Negative & Estimate & 0.95 & 0.95 \\
Transmission & & & \\
\hline
\end{tabular}

are essentially the same for the $\mathrm{H}^{\circ}$ and $\mathrm{D}^{\circ}$ cases because the relevant cross sections have the same scaling with nucleon energy.

\section{COMPONENT TECHNOLOGIES}

The beamline concept was formulated after surveying candidate technology options ${ }^{5-9}$ for the principal injector components. Although no detalled component design was attempted, component sizes were estimated and initial evaluations on possible system effects of incorporating varlous technologies were made. Table IV indicates the component technologies which would be allowed within the constraints of Table II and the envelope of Fig. 6 .

The first option entered in each column is the technology assumed in deriving the performance estimate of Table III. Substitution of a volume source, with its signiflcantly lower gas efficiency, would cause increased premature stripping within the accelerator, resulting in additional accelerator loading, more power in the less-than-full energy portion of the neutral beam, and less infected neutral power. A capillary stripper-separator-dump ${ }^{6}$ would decrease the extractor beamlet packing density such that a larger source would be needed or less power would be generated. The use of 
Table IV Allowable injector component options

\begin{tabular}{lccc}
\hline Source & Accelerator & Stripper & Separator/Dump \\
\hline Surface $^{*}$ & Plerce $^{*}$ & Standard gas & Magnetic* \\
Volume & ESQ & Cooled gas & Electrostatic \\
& & Capillary gas & Capillary tube \\
& & Plasma & \\
& & & \\
& &
\end{tabular}

${ }^{*}$ Basis for performance estimate.

a plasma stripper would yleld a larger neutral fraction and therefore more injected neutral power.

of all the component technologies surveyed, only an RFQ accelerator is questionable as a candidate for application on the proposed negative ton system. There is rf power on-site at about the right frequency, but the $\sim 4$ meters required for existing highcurrent RFQ concepts 7,8 would violate length constraints. Although these RFQ concepts are for considerably higher energies (several $\mathrm{MeV}$ ), the gentle-bunching function in an RFQ prevents a straightforward decrease in length with decreasing energy. We speculate that a shorter RFQ could be designed whlch compromises bunching and therefore has reduced acceleration efficiency. Th1s possibility has not been explored.

\section{SUMMARY}

A concept for a negative Ion-based NBI for DIII-D has been described and has the following attributes:

- It would extend NBI physics data base on heating and current drive for more relevance to ITER.

- It would have an acceptable impact on DIII-D operations.

- With the possible exception of an RFQ, there would be no restrictions on the incorporation of the many candidate negative ion component technologies.

The authors gratefully acknowledge W. S. Cooper of LBL for discussions and ideas. 
1. C. D. Boley, R. K. Janev and D. E. Post, Phys. Rev. Lett. $\underline{52}$, 534 (1984).

2. D. K. Bhadra and Jinchoon Kim, Proc. of the $13^{\text {th }}$ Symp. on Fusion Engineering, Knoxville (1989).

3. H. L. Berk, W. Horton, Jr., M. N. Rosenbluth and, P. H. Rutherford, Nuclear Fusion 15, 819 (1975).

4. R. B. Campbell, paper 2C27, 1988 Sherwood Theory Conference, Gatlinburg, 1988.

5. 0. A. Anderson, Proc. of the Tenth Int. Conf. on the Application of Accelerators in Research and Industry, Denton, Texas (1988).

6. A. J. T. Holmes, Proc. of the International Conference on Ion Sources, LBL (1989).

7. R. H. Stokes, T. P. Wangler, and K. R. Crandall, Proc. of the 1987 IEEE Particle Accelerator Conf., Chicago (1987).

8. W. R. Becraft, J. H. Whealton, T. P. Wangler, A. Schempp, G. E. McMichael, et al., Proc. of the 1988 Inear Accelerator Conf., Willlamsburg (1988).

9. W. S. Cooper, "A Neutral Beam Development Plan for CIT," unpublished (1988). 


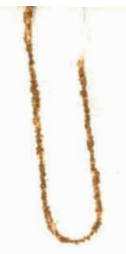

\section{DO NOT MICROFLL \\ COVER}

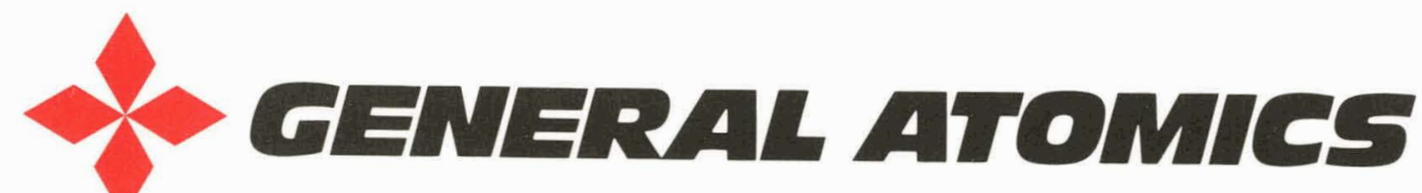

P.O. Box 85608 - San Diego, CA • 92138-5608 (619) 455-3000 